\title{
An autopsy study of 64 homicidal crushing injuries to head (Bludgeon Injury)
}

\author{
Dinesh $\mathrm{Rao}^{{ }^{*}}$
}

1 Professor \& HOD, Department of Forensic-Medicine, TOMCH, Bangalore-562107.India. Ex-Director and chief forensic Pathologist, Jamaica.

*Corresponding Author: Dr. Dinesh Rao, Professor \& HOD, Department of Forensic-Medicine, TOMCH, Bangalore-562107.India. Ex-Director and chief forensic Pathologist, Jamaica. Email: dineshrao22@yahoo.com. Ph +919741360206

Received: September 03, 2021; Accepted: September 27, 2021

\section{Abstract}

This Prospective Study was conducted during the period 2009 to November 2020.A Total of 9684 Autopsies were Conducted during this period, Homicidal Fatal Crush Injury Head cases comprised of 64 cases, i.e. $0.66 \%$ of Cases. The Majority of the Victims were Females,72\% [n-46] and Males $28 \%$ cases.Sex related Motives were the Major Factor in Female[24 cases] Homicides, Followed by Loot in 09 cases. In Males Loathing and Loot were the main factors contributing in 6\& 4 cases. The Majority of the Females Victims Occupation was Sex Worker/Prostitutes \& Labor Class comprising $27 \% 09$ cases respectively. In Majority of Female Homicides the Murder Weapon was recovered next to the body in 23 of the cases whereas the same was recovered in only 03 cases in Males. Granite Block or Boulder Formed the Major Choice of Bludgeon or Murder Weapon in 34 cases of Female Victims and 08 cases of Male Victims. The Majority of the Female Victims [22 cases] were Bludgeoned on the Mud floor. The Majority of the Victims in Both the sexes belonged to the age group 21-30 years, contributing to 9 \& 21 cases in Male and Females Respectively.

Keywords: Homicidal Crushing Head Injury, Bludgeon, Murder Weapon, Granite Blocks, Cement Blocks, Hammer, Motives, Sex Worker, Laborer.

\section{INTRODUCTION}

Crushing Head injury, as the name implies, occurs when the brain and skull are crushed-usually between two hard objects [1-3]. The more forceful the crushing is, the more severe damage will be, but damage also depends on factors such as the location of the injury and Hardness of the Impacting Object [Bludgeon]. This Prospective Study was conducted during the Period 2009 to November 2020.

A crushing brain injury causes damage to the brain, blood vessels, and skull, each of which can be life-threatening: A skull fracture exposes the brain to further damage by robbing the brain of its protective case. Further, fragments of the skull may puncture the brain or blood vessels, causing more damage. Most crushing skull injuries cause severe bleeds, as blood vessels are crushed under the weight of the skull or the objects that led to the injury. If severe enough, you can bleed to death. Even when the bleeding is relatively minor, it can cause damage to the brain or to surrounding structures, such as the spinal cord or sinuses. The brain itself usually suffers extreme injuries as a result of a crushing brain injury. The severity of the damage depends upon the force behind the crushing, as well as the location of the damage.
In the United States, TBI accounts for approximately $40 \%$ of all deaths from acute injuries and approximately 200,000 victims of TBI require hospitalised care annually ${ }^{[4]}$. In Singapore, 'external causes of morbidity and mortality' (ICD10: V01-Y89) is the fifth principal cause of death ${ }^{[5]}$.

Traumatic brain injuries (TBI) occur when sudden trauma damages the brain and disrupts its normal function. It can cause significant disability and mortality and represents a public health concern in both developed and developing countries.

Compression or crush injury to the head is less commonly seen. A crush injury occurs when a body part is subjected a degree of force or pressure, usually after being trapped between two heavy objects or hard surfaces. The bilateral application of static forces on the head can occur in any region, however it often occurs the bitemporal region ${ }^{[6-8]}$.

Hence, The Present Study is Unique given the Long Duration of Study \& More number of Cases Peculiar to Homicidal Fatal Crushing Injury to Head. All the Cases Studied in the study were Found Dead and never Treated Clinically, hence no Clinical Evaluation was done in all the cases. 


\section{MATERIALS \& METHODS}

All the cases reported were Reported at the request of Coroner \& The Autopsy was carried out in different Country and Different States, during the Period 2009 to 2020.

All the Cases Reported were Found Dead Cases. The Details of the Victims and the Circumstances were retrieved from the Documents, Photographs and at times by Visiting the Death Scene. The Injuries to Other Parts of the Body Fatal and Non Fatal are Excluded, only Homicidal Fatal Crushing Head Injuries were Included in the Study. The Data, thus obtained are registered in the Designated Register as and when the Cases were Reported. The Results thus obtained are carefully studied and Analyzed in the study.

\section{RESULTS}

Figure no 01 Indicates the Number of Autopsies Conducted during the Period of Study. A Total of 64 Homicidal Fatal Crush injury to Head were reported out of the 9684 Autopsies Conducted during the Period between 2009 to November 2020. All the Cases reported were brought Dead or Found Dead Victims.

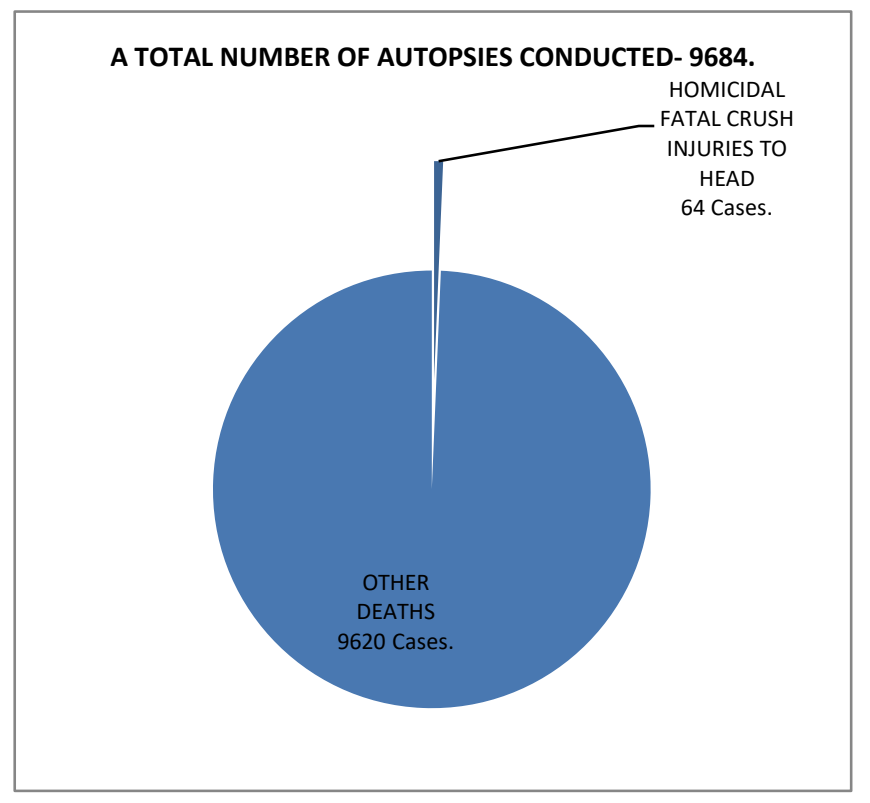

Figure 1: Total Number of Autopsies Conducted During the period of Study.

Figure no 02, indicated the Sex Distribution of the Victims. A Majority of the Victims belonged to Female Sex, Male contributed to only 18 number of Cases.

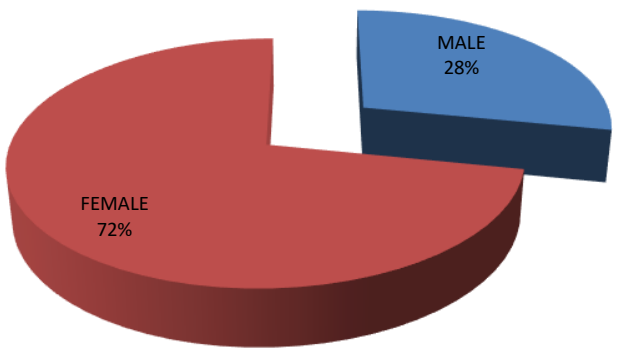

Figure 2: Sex Distribution of the Victims.

Table no 01 Indicates Different Motives behind the Fatal Homicidal Crush injuries in both Male and Female. In Majority of the Females victims [n-27], Sex Related Motives like Extra Marital Affair, Love Relationship \& Betrayel, Infidelity, Affairs were recognized as the Main Motives. Whereas in Males the Loathing or Enmity Motives dominated in 06 cases. Land or Property Disputes or Alcohol \& Drugs did not contribute to Female Homicides. Homicides arising out of Loot contributed to Increased number of Homicides [09] Than Males. In Males Loot Homicides contributed to only 04 number of cases. However, with the recovery of 10 Unknown Bodies the Motives could not be Established.

Table 1: Motives Behind Bludgeon Injury.

\begin{tabular}{|l|l|l|l|}
\hline SI no & Causes & Male & Female \\
\hline 01 & Loathing/Enmity & 06 & 04 \\
\hline 02 & For Alcohol/Drugs & 02 & 00 \\
\hline 03 & Sex Related & 01 & 27 \\
\hline 04 & Loot & 04 & 09 \\
\hline 05 & Land/Property Dispute & 01 & 00 \\
\hline 06 & Unknown & 04 & 06 \\
\hline 07 & Total & 18 & 46 \\
\hline
\end{tabular}

Table no 02 reflects the Occupational Background of the Victims. The Majority of the Female Victims [24 cases] occupation were Sex workers or Prostitutes, whereas only 01 Sex Worker was Bludgeoned. In males Majority of the Victims [06 cases] belonged to Worker or Labour class. Beggar or Destitute, Student and Drug Traffickers were also victims and contributed 02 cases each. The Second high number of Female Victims belonged to Working or Labour Class [09 cases], though more number than Males [06 cases]. 
Table 2: Occupational Details of the Victims.

\begin{tabular}{|l|l|l|l|}
\hline SI no & Occupation & Male & Female \\
\hline 01 & Beggar/Destitute & 02 & 06 \\
\hline 02 & Prostitute/Sex Worker & 01 & 24 \\
\hline 03 & Laborer/Worker & 06 & 09 \\
\hline 04 & Gang Affiliations & 03 & 01 \\
\hline 05 & Student & 02 & 01 \\
\hline 06 & Unknown & 04 & 06 \\
\hline 07 & Drug Trafficker & 02 & 00 \\
\hline
\end{tabular}

Table no 03 indicates the Place of Recovery of the Murder Weapon, the Bludgeon. The Majority of the Murder Weapon was recovered within 5-20 meters of the Recovery of the body, 12 \& 15 respectively in Males and Females. In Majority of Female Homicides the Murder Weapon was recovered next to the body in 23 of the cases whereas the same was recovered in only 03 cases in Males. However, in 3 \& 5 Homicide cases, the Murder weapon was recovered at 21-50 meters of Male \& Female Victims Respectively. In 03 Cases and 01 cases of Female \& Male Victims the Murder Weapon was Never Found in the vicinity of the Body, when recovered.

Table 3: Place of Recovery of Murder Weapon [Bludgeon].

\begin{tabular}{|l|l|l|l|}
\hline SI no & Murder Weapon Recovery & Male & Female \\
\hline 01 & Next to Body & 03 & 23 \\
\hline 02 & Within 5-20meters & 12 & 15 \\
\hline 03 & $21-50$ Meters & 03 & 05 \\
\hline 04 & Not Found & 01 & 03 \\
\hline
\end{tabular}

Table no 04 Describes the Kind of Murder Weapon, Granite Block or Boulder Formed the Major Choice of Bludgeon or Murder Weapon in 34 cases of Female Victims and 08 cases of Male Victims. This was followed by Cement Block as Fourth Choice in 10 cases of Female Victims and 05 Cases of Male Victims. Hammer was used in 02 cases of Male Victims whereas it was never used in Female Killings. Other Kinds of Bludgeon Used was Metal Rod/Pipe in 3 \& 2 cases of Male \& Female Victims Respectively.

Table 4: Kind of Bludgeon [Murder Weapon].

\begin{tabular}{|l|l|l|l|}
\hline SI no & Type of Murder Weapon & Male & Female \\
\hline 01 & Granite Boulder/Block & 08 & 34 \\
\hline 02 & Cement Block & 05 & 10 \\
\hline 03 & Hammer & 02 & 00 \\
\hline 04 & Metal Rod/Pipe & 03 & 02 \\
\hline
\end{tabular}

Table no 05-Describes the Different Type of Locations on which the Victim was Bludgeoned. The Majority of the Female Victims [22 cases]. Were found to be Bludgeoned on the Mud Floor. This was followed closely in Both sexes, the Victims were Bludgeoned on Road [Cement/Tar] in 07 \& 09 cases, Males \& Females Respectively. The Other preferred Location wherein Female Victims were Bludgeoned was Garden/Lawn Area in 10 cases, whereas only 03 cases of Males were found in this Locations. Play Ground, Cement Floor and Tiled house formed other types of Locations, only one cases each were found on Tiled House \& Cement Floor in Males Whereas Two Cases
Each, was reported in Females. Two cases of Males were Reported on Playground whereas only 01 case was reported on Playground in Females.

Table 5: Describes the Different Type of Locations on which the Victim was Bludgeoned.

\begin{tabular}{|l|l|l|l|}
\hline SI no & Locations & Males=18 & Females-46 \\
\hline 01 & Tar/Cement Road & 07 & 09 \\
\hline 02 & Tiled House & 01 & 02 \\
\hline 03 & Play Ground & 03 & 01 \\
\hline 04 & Garden/Lawn & 03 & 10 \\
\hline 05 & Cement Floor & 01 & 02 \\
\hline 06 & Mud Floor & 03 & 22 \\
\hline
\end{tabular}

Table no 06. Describes the Different Age group of the Victims Reported. The Majority of the Victims in Both the sexes belonged to the age group 21-30 years, contributing to $9 \& 21$ cases in Male and Females Respectively. This was followed by individual belonging to 31-40 years, with 04 \& 11 cases in Males \& Females Respectively. Hence it can be inferred that Females were the Major Victims in the $3 \& 4^{\text {rd }}$ decade of Life. The individuals in both Sexes below 01years and above 60 were never affected. The least Age group affected were those belonging to $5^{\text {th }} \& 6^{\text {th }}$ Decade of Life contributing to Two cases in Males \& 07 cases in Females.in the Second Decade of Life 03 cases \& 07 cases were reported in Males and Females Respectively.

Table 6: Age Group Affected.

\begin{tabular}{|l|l|l|l|l|}
\hline SI no & Age Group & Male -18 & Female-46 & Total Number-64 \\
\hline 01 & $0-10$ & Nil & Nil & Nil \\
\hline 02 & $11-20$ & 03 & 07 & 10 \\
\hline 03 & $21-30$ & 09 & 21 & 30 \\
\hline 04 & $31-40$ & 04 & 11 & 15 \\
\hline 05 & $41-50$ & 01 & 05 & 06 \\
\hline 06 & $51-60$ & 01 & 02 & 03 \\
\hline 07 & $61-70$ & 00 & 00 & 00 \\
\hline
\end{tabular}

\section{DISCUSSION}

This present study was carried out during the period 2009 to 2020. A total of 9684 cases were conducted during this period of which only 64 cases reported as Homicidal Fatal Crushing injury to the Head, as seen in Figure no 01 . This present study is Unique to itself for being first of its kind. Because Homicidal Fatal Crushing Injury to Head is Unusual and Rarely Reported though Few Studies were conducted but they Included only Characterize Clinical features and Preventive Measures Study $[9,10]$.

But the Study included only Those Crushing Injuries to Head which are Fatal and Homicidal, this Makes it Unique as No study in the World had ever attempted to Examine and Analyze Information emanating out of this Homicides. In a Study conducted by Sawachi [11] The Individuals Examined were related Industrial Accidents and Motor Vehicle Accidents contrary to the present study wherein only Homicides were Examined. Similarly, in another study conducted by Duhamie et al., [12], Seven Crushing Head injury cases were studied, those 
involving Motor Vehicle Accidents, but the major aim of the Study was to Describe Evaluation and Treatment Complexity. Hence none of the Study known was attempted to Examine Homicidal Fatal Crushing Injury to Head, unlike the Present Study. In the present Study only 64 cases were reported out of 9684 cases Autopsied, this Data clearly speaks volumes about the Rarity of such cases and the difficulty in the availability of Study Material. Of the 64 cases Females formed the Major number of Cases [Figure no 02] contributing to $72 \%$ of cases[n46].

The Major Age Group affected in Both Sexes were 21-30 years [Tabel no 06] with 21 \& 09 cases Respectively in Females \& males. This was followed by age Group 31-40, wherein 04 \& 11 cases reported from Male \& Female Sexes. This indicates that, Adults were more Prone.

Individuals below 10 years and above 60 years were never Affected. [Table no 06] These results infer that Children's and Elderly not affected due to the possibility they were excluded from the Occupation described above \& the possibility of them being unaffected the Motives described above.

But in Studies Conducted by Chamber et al., [13] \& Greenwald [14], Males Suffered Twice than the Females and Majority of the Victims were above 70 years, their studies were based on Morbidity out of Traumatic Brain Injuries, which is deviating from the represent study, wherein Only Homicides were Examined.

In another studied conducted by Jing Zongh Wee et al. [9], he noticed $75 \%$ of his Victims Were Males, deviating from the Present Study, but his subjects of Study were Non Fatal Injuries and were limited for Clinical evaluation of Traumatic Brain injuries. However in his study the age group affected, though Non Fatal injuries, were close to those made in the resent study.

Hence it is important to understand the Motives for such Homicidal Crushing Head Injury. In the present Study, [Table no 01] Sex related Motives formed the Major number of homicidal Deaths in Females, whereas Loathing formed the major number of Deaths in Males [n-6]. Hence this clearly indicated that in most of the Female Victims the Investigating officer should always rule out the possibility of Sexual Motives before considering other Motives like Property disputes and Loathing in Females. Sexual Motives includes those due to Infidelity, Jealousy, Extramarital Affairs, Love and Lust.

Whereas in Males Loathing is the First Motives the Investigator should look into in cases of Homicidal Crushing Head injury. The other Commonest causes of Death in Females reported was Death during Loot, possibly the presence of Valuables with Females and the Fear of Getting Caught might have prompted the Culprit to resort to attack on Female Victims. The present study also highlighted the fact that Female Victims were never due to Drugs or Alcohol or associated with Property Disputes.

The Majority of Female Victims were directly or indirectly related to Sex Work in 24 cases and other major group of Females Victims belong to the Working class [Laborers], in 09 cases. This clearly confirms the fact that issues arising out of Sex Trade and Worker Related issues are the major Triggering Factors to commit this dastardly act. Other Occupation related Female Deaths were those belonging to the Beggar Group or Destitute [06 Cases] and 02 cases in Males. This were the deaths wherein the Motives are not clearly Understood and were strange in Nature. Hence further studies are recommended to understand the Factors responsible to Their Deaths as Motives are not Understood in this class of Individuals.
In the Present Study, A total of 10 reported cases were Not Identified or Unknown Cases, of which 06 were Females. In this Victims the Occupational Details or Motives was never Established nor Understood despite all reasonable efforts by the Investigating Officers. Though Unanswered questions still haunt as Why were They Bludgeoned \& Who were They?

In Majority of Homicidal cases involving Females the Murder weapon or the Bludgeon was found next to the body in 23 of the Female Victims, wheras it was found within 5-20 meters radius in 15 of the Female Victims, whereas in Males the Bludgeon was found near the body in only 3cases and 12 case the Bludgeon was found in 5-20 meters radius.[Table no 03] The other Major observation which could have an impact on understanding this Fatal Crushing injury deaths is the missing Murder Weapon from the Death Scene in 1 \& 03 cases involving Male and Females Respectively. This indicates the possibility that the Death Scene and Crime Scene are Different.

The Major Choice of Weapon or Bludgeon used was Granite Blocks, this contributed to 34 deaths in Females and 08 in Males.[Table no 04] The possibility of easy availability within the vicinity is the only factor which has encouraged the assailants to prefer it. The other choicest weapon or Bludgeon was the Cement Blocks, in the present days involving aggravated Construction activity, this Cement Blocks is another easily accessible Bludgeon and the number of Laborers falling victims, 06 \& 09 in Males and Females Respectively, confirms the Same. Hammer is another Kind of Murder weapon used in the Crushing Head injury of 02 Male Victims. But No such Weapon used in killing of any of the Female Victims.

The Commonest Location preferred were the Mud floors, in 22 female Victims whereas in Male Victims, Tar or Cement Roads [Table no 05], were the major Location preferred in 07Victims. The Least Favorable Location were Cement Floor \& Tiled House with 1 \& 2 cases each, in Male \& Female Victims Respectively. Location plays a Very important role in development of the Severity of Injury, because for the Injury to Develop there should be Compression between Two Hard Objects, harder the Object and more will be the Damage $\left[{ }^{13,14]}\right.$.

\section{CONCLUSION}

Hence, this study a First of its kind, wherein Crushing Head Injury Due to Homicide was ever attempted, The Author understand the Non-Availability of Similar studies elsewhere so as to compare with the Result of his Study. There are Studied reported on Crushing Head Injury to Motor Vehicle Accidents \& Industrial Accidents, but none examined for Homicides. This Study had made all possible efforts to describe the Character of the Homicidal Crushing Injury and the Author Recommends more such Studies for better Understanding of the Forensic Evaluation of this Deaths.

\section{Conflict of Interest}

We declare that we have no conflict of interest.

\section{Financial Support}

None declared. 


\section{REFERENCES}

1. Chambers J, Cohen SS, Hemmenger L, Prall JA, Nichols JS. Mild traumatic brain injury in low risk trauma patients. J Trauma. 1996; 41:976-80.

2. López-Guerrero AL, Martínez-Lage JF, González-Tortosa J, Almagro MJ, García-Martínez S, Reyes SB. Pediatric crushing head injury: biomechanics and clinical features of an uncommon type of craniocerebral trauma. Childs Nerv Syst. 2012; 28(12):2033-40.

3. Echizenya K, Satoh M, Nakagawa T, Koiwa M, Abe H. Bitemporal compression injury caused by static loading mechanism. Report of two cases. J Neurosurg. 1985; 62(3):438-41.

4. Thurman DJ, Alverson C, Dunn KA, Guerrero J, Sniezek JE. Traumatic brain injury in the United States:A public health perspective. J Head Trauma Rehabil. 1999; 14:602-15.

5. Ministry of Health. Principal causes of death. [Accessed May 4 2014]. at: https://www.moh.gov.sg/content/moh_web/home/statistics/He alth Facts Singapore/Principal Causes of Death.html.

6. Ommaya AK, Goldsmith W, Thibault L. Biomechanics and neuropathology of adult and paediaric head injury. $\mathrm{Br} J$ Neurosurg. 2002; 16:220-42.

7. Gonzalez Tortosa J, Martinez-Lage JF, Poza M. Bitemporal head crush injuries: Clinical and radiological features of a distinctive type of head injury. J Neurosurg. 2004; 100:645-51.

8. Holbourn AH. Mechanics of head injuries. Lancet. 1943; 2:43841.

9. Jing Zhong Wee, MBBS, Yun Rui Jasmine Yang, MMed, MBBS, Qian Yi Ruth Lee, MBBS, Kelly Cao, Chin Ted Chong, MMed, FANZCA. Demographic profile and extent of healthcare resource utilisation of patients with severe traumatic brain injury: still a major public health problem. Singapore Med J. 2016; 57(9):491496.

10. José Gonzalez Tortosa, Juan F Martínez-Lage, Máximo Poza Bitemporal head crush injuries: clinical and radiological features of a distinctive type of head injury. J Neurosurg. 2004; 100(4):64551.

11. S Sawauchi, K Yuhki, T Abe, Crushing head injuries: report of six cases. No Shinkei Geka.1999; 27(6):557-61.

12. AC Duhaime, M Eppley, S Margulies, KL Heher, SP Bartlett Crush injuries to the head in children. Neurosurgery. 1995; 37(3):401-6; discussion 407

13. Chambers J, Cohen SS, Hemmenger L, Prall JA, Nichols JS. Mild traumatic brain injury in low risk trauma patients. J Trauma. 1996 41:976-80.

14. Greenwald BD, Burnett DM, Miller MA. Congenital and acquired brain injury. 1. Brain injury: epidemiology and pathophysiology. Archives of Physical Medicine and Rehabilitation. 2003;84(3 Suppl 1):S3-7. 